\title{
Derleme
}

Mersin Univ Saglık Bilim Derg 2019;12(1):143-149

doi:10.26559/mersinsbd.531295

\section{Raynaud Fenomeni üzerine genetik yapı, östrojen ve toksik ajanların klinik etkileri}

\author{
Merih Akkapulu, Ali Erdinç Yalın
}

Mersin Üniversitesi Eczacilik Fakültesi

Öz

Raynaud Fenomeni (RF) soğuk kaynaklı vazokonstrüksiyonla karakterize bir hastalıktır. Bu güçlendirilmiş vazokonstrüksiyon, sempatik sinir sistemi yoluyla soğumaya karşı bir refleks cevabı ve Alfa2C $\left(\alpha_{2 c}\right)$ adrenoreseptörlerinin lokal aktivasyonu ile gerçekleşmektedir. Bu hastalık klinik olarak primer ve sekonder olarak sınıflandırılmaktadır. Primer RF idiyopatiktir ve hastalığın en yaygın şeklidir. Sekonder RF, otoimmün veya kanser gibi hastalıklara eşlik edebileceği gibi, sigara içimi ya da bazı ilaçların kullanımı da sebebiyet verebilmektedir. Etkilenen bireyler, soğuk ve stresin tetiklemesiyle birlikte, genellikle el parmaklarında, klasik üç renk değișikliğiyle (solukluk, siyanoz ve hiperemi) ilișkili olan vazospastik ataklardan muzdarip olmaktadırlar. Epidemiyolojik çalışmalardan elde edilen veriler, RF prevalansı ile ilgili ilginç bulgular ortaya koymuştur. Yaşları aynı olan kadınların, erkeklere göre anlamlı olarak daha yüksek bir insidansa sahip olduğu belirlenmiştir. Bu derlemede, östrojenin, genetik yapının ve kimyasal ajanların RF üzerine olan etkileri tartışılmıştır. Sonuç olarak, bu hastalığa neden olan birçok faktör açılklanmasına rağmen, RF'nin başlangıcının ve ilerlemesinin altında yatan moleküler mekanizmaların aydınlatılması için daha fazla araştırmaya gereksinim duyulmaktadır.

Anahtar Kelimeler: Raynaud fenomeni, vazospazm, Alfa2 $\left(\alpha_{2}\right)$ adrenoreseptörler, östrojen

\section{The clinical effects of genetic structure, estrogen, and toxic agents on Raynaud's Phenomenon}

\begin{abstract}
Raynaud's phenomenon (RP) is characterized by cold-induced vasoconstriction. This enhanced vasoconstriction is achieved by a reflex response to cooling through the sympathetic nervous system and by local activation of Alpha2C $\left(\alpha_{2 c}\right)$ adrenoreceptors. This disease is clinically classified as primary and secondary. Primary RP is idiopathic and is the most common form of the disease. Secondary RP may be associated with diseases such as autoimmune diseases or cancer, and smoking or the use of certain medications may also be cause. Affected individuals suffer from vasospastic attacks associated with classical three colour changes (paleness, cyanosis, and hyperemia), often triggered by cold and/or stress. The data from the epidemiological studies revealed interesting findings related to the prevalence of RP.
\end{abstract}

Yazının geliş tarihi:22.02.019 Yazının kabul tarihi:16.03.2019

Sorumlu yazar: Merih Akkapulu, Mersin Üniversitesi Eczacilik Fakültesi Yenișehir Kampüsü 33160 Yenişehir/ Mersin, Türkiye, e-posta: mrhakkapulu@gmail.com, Tlf: 05372499457 
It was determined that women with the same age had a significantly higher incidence than men. In this review, the effects of oestrogen, genetic structure and chemical agents on RP were discussed. As a result, although many factors have been described causing this disease, further research is needed to elucidate the molecular mechanisms underlying the onset and progression of RP.

Keywords: Raynaud's phenomenon, vasospasm, Alpha2 $\left(\alpha_{2}\right)$ adrenoreceptors, estrogen

\section{Giriş}

Kutanöz arteriollerin soğuk kaynaklı vazokontrüksiyonu, vücudu aşırı ısı kaybından korumak için kanı yüzeysel dolaşımdan iç organlara yönlendiren fizyolojik bir süreçtir. ${ }^{1} \mathrm{Bu}$ daralmaya noradrenalinin artmasının yanı sıra vaskülatörün artmış olan duyarlılığı aracılık etmektedir ${ }^{1,2}$. Bu soğuk kaynaklı daralmanın artması, Raynaud Fenomeni (RF) olarak bilinen patolojik bir durumun ortaya çıkmasına neden olmaktadır. ${ }^{3}$

$\mathrm{Bu}$ hastalık klinik olarak primer ve sekonder olarak sinıflandırılmaktadır. ${ }^{4}$ Primer RF idiyopatiktir ve hastalığın en yaygın şeklidir. ${ }^{5}$ Sekonder RF, otoimmün veya kanser gibi hastalıklara eşlik edebildiği gibi, sigara içimi ya da bazı ilaçların kullanımı da sebebiyet verebilmektedir. ${ }^{6}$ Skleroderma teşhisi konulan hastaların \%95'nin RF tanısı almış olması bu kanıyı doğrulamaktadır. ${ }^{7} \mathrm{RF}$, genel nüfusun \%10'unu etkilemektedir. ${ }^{8}$ Etkilenen bireyler, soğuk ve stresin tetiklemesiyle birlikte, genellikle el parmaklarında, klasik üç renk değişikliğiyle (solukluk, siyanoz ve hiperemi) ilişsili olan vazospastik ataklardan muzdarip olmaktadırlar. ${ }^{9}$ Burun, ayak parmakları, kulak memesi gibi diğer distal vücut organlarının da etkilendiği bildirilmiştir. ${ }^{4}$

RF'ni teşhis etmek için kullanılabilecek farklı belirtiler olsa da, bazı parametrelerdeki değişiklikler yararlı olabilmektedir. $\mathrm{Bu}$ parametreler içerisinde RF tanısı almış hastaların serolojik testleri, artan endotelin-1 düzeyleri, tümör nekrozis faktör-alfa (TNF- $\alpha$ ), fibrinojen, trombosit faktörü (PF-4) ve von Willebrand faktörü (vWF) girmektedir. RF hastalarında magnezyum iyonları ve S-nitrozotiyol düzeylerinin etkilenmemiş bireylere göre azaldığı görülmüştür. ${ }^{10}$
RF'nin patogenezinde rol oynayan mekanizmaları incelemek ve açıklamak için birçok hipotez önerilmiştir. Son çalışmalar, bu hastalığın mozaik teorisine güçlü destek vermektedir. ${ }^{11} \mathrm{Bu}$ teori, yerel, nöronal ve hormonal aracıları içermektedir. ${ }^{2} \mathrm{Bu}$ aracıların herhangi birinin bozulmuş işlevi noradrenaline yanıt olarak kutanöz arterlerin aşırı miktarda daralmasına sebebiyet vermektedir. ${ }^{13}$ Noradrenalin, damar düz kas hücrelerinin yüzeyinde bulunan adrenerjik reseptörlere bağlanarak etkilerini ortaya çıkarmaktadırlar. ${ }^{14}$ Üç tip adrenerjik reseptör (AR) bulunmaktadır: Alfa1, Alfa2 ve Beta2 $\left(\alpha_{1}, \alpha_{2}\right.$ ve $\left.\beta_{2}\right)$. Vasküler yatağa bağlı olarak Beta1 ve Beta3 $\left(\beta_{1}\right.$ ve $\left.\beta_{3}\right)$ adrenoreseptörler bulunmaktadır, ancak genellikle Beta2 adrenoreseptörlerden daha düşük bir ifadeye sahiptirler. ${ }^{15}$ Alfa1 ve Alfa2 adrenoreseptörler vazokonstrüksiyondan sorumlu iken Beta2 adrenoreseptör sadece vazodilasyondan sorumludur. ${ }^{16}$ Alfa1 adrenoreseptörler vasküler ağaç boyunca geniş bir ekspresyon şablonuna sahipken, $\alpha_{2}$ adrenoreseptörler baskın olarak daha küçük kan damarları veya arterioller de bulunmaktadırlar. ${ }^{17}$

Yapılan çalıșmalar, kutanöz arterlerin lokal soğutma ile indüklenen daralmada Alfa2 adrenoreseptörlerin belirgin rollerini işaret etmektedir. Lokal soğutmanın vazodilatasyona neden olduğunu ve aynı zamanda Alfa1 adrenoreseptörler aracılığıla vazokonstrüksiyonu inhibe ettiğini de belirtmektedir. ${ }^{18,19}$

Moleküler, genetik ve farmakolojik çalışmalar, Alfa2 adrenoreseptörlerin üç alt türünün varlığını göstermektedir: Alfa2A, Alfa2B ve Alfa2C $\left(\alpha_{2 A}, \alpha_{2 B}\right.$ ve $\left.\alpha_{2 C}\right)$. Bu alt tiplere karşılık gelen genler üç farklı kromozom üzerinde bulunur ve hepsi de inhibitör hetero-trimerik $G$ proteinlerine bağlanır.20 Alfa2 adrenoreseptör aracılı 
soğuk indüklü vazokonstrüksiyondan sorumlu belirli alt tip için yapılan araştırmalar, Alfa2A adrenoreseptörlerin, soğuk kaynaklı daralmada herhangi bir rol oynamadığını göstermiştir. ${ }^{21}$ Bazı raporlar, RF'de vazospazmlar için bir tedavi seçeneği olarak Alfa2B adrenoreseptör antagonistlerinin potansiyel kullanımını işaret etmektedir. ${ }^{20}$ Fakat, RF'nin tedavisinde Alfa2B adrenoreseptör antagonistlerinin rolünü destekleyen güçlü kanitlar bulunamamıştır. Alfa2 adrenoreseptör alt tiplerinden olan $\alpha_{2 C}$ adrenoreseptör'ün iki ana nedenden dolayı körelmiş bir reseptör olduğu düșünülmüștür. Birincisi, $\quad$ Alfa2C adrenoreseptörlerin hücre içi bölme içinde ayrıştırılamamasıdır ve böylece işlevlerinin immünohistokimya analizleri ile tespit edilememesidir. ${ }^{20}$ İkincisi ise, Alfa2C adrenoreseptörün ne nakavt ne de transgenik farelerde büyük bir değişiklik gösterememesidir; her ikisi de canll, verimli ve neredeyse normal bir şekilde kalmışlardır. ${ }^{22}$ Öte yandan, karşıt görüşler ortaya atılmıştır. Birincisi, Alfa2C adrenoreseptörlerde, diğer adrenoreseptörlerde bulunmayan korunmuş alanların bulunmasıdır. İkincisi, görünüște normal fenotip, diğer Alfa2 adrenoreseptörler tarafindan telafi edilmesine bağlı olabilir ve üçüncüsü, $\alpha_{2 C}$ adrenoreseptörlerin farklı dokulardaki hücrelerde farklı şekillerde eksprese edilebilmesidir. ${ }^{20}$

Alfa2C adrenoreseptör'ün ilginç ve kendine özgü özelliği endoplazmik retikulum (ER) ve golgiden hücre zarına translokasyon yapabilmesidir. $\mathrm{Bu}$ durum, ligandı için mevcut olan reseptörü oluşturmaktadır. Günümüzde membran lokalize reseptörler agonistleri ile kolayca etkileşime girebilir, aktive olur ve noradrenaline yanıt olarak kutanöz vazokonstrüksiyonu uyarırlar. ${ }^{23}$ Aslında, kutanöz arteriollerin soğuk kaynaklı büzülmesinin Alfa2C adrenoreseptörlerin artan aktivitesine bağlı olduğu açıklanmaktadır. $\mathrm{Bu}$ şekilde, Alfa2C adrenoreseptörleri, RF'de gözlemlenen artmış vazokonstrüksiyonda önemli bir rol oynadığı görülmektedir. ${ }^{24}$

$\begin{array}{cr}\text { Alfa2C } & \text { adrenoreseptör } \\ \text { translokasyonunun } & \text { gerçekleștiği }\end{array}$

mekanizmada birçok etken bulunmaktadır. Buna örnek reaktif oksijen türleri (ROS), Rho/Rho kinaz ve aktin hücre iskeleti verilebilir. Rho/Rho kinaz yolunun, hücrelerin soğuğa maruz kalmasından birkaç dakika sonra aktif olduğu bildirilmiştir. Aktif olan Rho, Alfa2C adrenoreseptörünün membrana mobilizasyonunu sağlayarak, soğuk kaynaklı vazokonstrüksiyonunu tetiklemektedir. $\mathrm{Bu}$ anlamda, Rho'nun "termosensör" olduğu anlaşılmıştır. ${ }^{24}$

\section{Raynaud Fenomeni ve Östrojen}

Epidemiyolojik çalışmalardan elde edilen veriler, RF prevalansı ile ilgili ilginç bulgular ortaya koymuştur. Yaşları aynı olan kadınların, erkeklere göre anlamlı olarak daha yüksek bir insidansa sahip olduğu belirlenmiştir.25 RF tanısı almış premenopozal kadınların erkeklere oranı 9:1'e yakın olduğu belirlenmiștir. ${ }^{26} \mathrm{Bu}$ durumda, hastalığın prevalansında cinsiyete dayalı bir unsur olduğu gösterilmiş ve böylece başlangıçta veya patolojisinde seks hormonlarının rolüne işaret etmiştir ve kadınlar için RF risk faktörü arasında olduğu belirlenmiştir. ${ }^{25} \mathrm{Bu}$ sonuç, kadınların erkeklere göre prevalansının yüksek olduğunu ortaya koyan meta-analiz çalışmasına dayanmaktadır. ${ }^{27}$ Özellikle, menopoz sonrası kadınlarda, menstüral döngü ve soğuk modüle dijital kan akışı arasında ilginç bir ilişki ile insidans daha yüksek bulunmuştur. ${ }^{11}$ Daha ileri çalışmalarda, östrojen replasman tedavisi (ERT) alan menopoz sonrası kadınlarda, ERT tedavisi almayan postmenopozal kadınlara oranla hastalığa yakalanma olasılığının daha yüksek olduğu ortaya konulmuştur. ${ }^{28} \mathrm{Bu}$ bulgular östrojenin premenopozal kadınlarda daha yüksek insidansı açıklayabileceğini göstermektedir. İlginç bir şekilde, östrojen tedavisi alan postmenopozal kadınlarda (östrojen ve progesteron birlikte), RF insidansı premenopozal kadınlarınkinden anlamlı bir şekilde yüksek bulunmamıştır. Bu durum, progesteronun östrojeni bu bağlamda etkisiz hale getirdiğini düşündürebilir. Fakat bu durum hala tam olarak ortaya konulamamıştır. ${ }^{29}$ 
Premenopozal kadınlarda, noradrenalin aracılı vazokonstrüksiyonun, orta evrede östrojenin erken evresine göre nispeten yüksek östrojen seviyesiyle karakterize olduğu belirtilmiştir. ${ }^{30}$ Üreme çağındaki insan ve sıçan dişilerinde yapılan çalışmalarda, erkeklere göre daha yüksek vasküler tepki saptanmıştır. İlginç olarak, $17 \beta$-östrodiol harici olarak desteklendiğinde erkek vasküler yanıt verme potansiyeli yüksektir. $\mathrm{Bu}$, östrojenin vazoreaktivite üzerinde doğrudan bir etkiye sahip olduğunu göstersede, bu durumu kuvvetlendirme mekanizmaları henüz açıklanamamıştır. ${ }^{31}$

Östrojenin, vazodilatör bir etkiye sahip olmasına rağmen, vücut sıcaklığını da düşürdügü belirlenmiştir. ${ }^{32} \mathrm{RF}$, bir vasküler termoregülatör kontrol bozukluğu olarak düşünüldüğünde, östrojenin hastalığa etkisi, özellikle genç kadınlarda RF'nin prevalansının daha yüksek olmasının yanı sıra, premenopozal kadınlarda soğuğa karşı aşırı duyarlılık gelişmiştir. ${ }^{33} \mathrm{Bu}$, östrojene tepki olarak vazomotor aktivitelerde cinsiyet farklılığı olduğunu ve bu farkın RF gibi vazospastik hastalıkların epidemiyolojisinde önemli bir katkı sağlayacağını belirlemiştir. ${ }^{34}$

Östrojenin, damar düz kas hücrelerinde Alfa2C adrenoreseptör ekspresyonunu arttırdığı ve sıçan kuyruğu arterlerinde soğuk tarafından uyarılmış vazokonstrüksiyona aracılı ettiği belirlenmiştir. Dikkat çekici veri, Alfa2 adrenoreseptörler arasında, sadece Alfa2C adrenoreseptör alt tipinin siçan kuyruğu arterlerinde farklı şekilde eksprese edilmesidir; bu durum dişilerde daha belirgindir. Ayrıca, insan damar düz kas hücrelerinde östrojenin Alfa2A adrenoreseptör ifadesinin modüle edemediği bilinmektedir. Alfa2C adrenoreseptörün, soğuk kaynaklı vazokonstrüksiyonun bütününe aracılık ettiği tespit edilmiştir. Yapılan çalışmalarda östrojenin, Alfa2C adrenoreseptör ekspresyonu, yüzey lokalizasyonunu ve fonksiyonunu arttırdığı doğrulanmıştır. Bu östrojen kaynaklı Alfa2C adrenoreseptör aktivitesini, sıçan kuyruğu arterlerinde kuvvetlendirilmiş soğuk indüklü vazokonstrüktif yanıt izlemiştir. Yapılan araştırmalar, östrojen ve RF arasında pozitif bir ilişki olduğunu vurgulamaktadır. ${ }^{35}$

\section{Raynaud Fenomeni ve Genetik}

Daha önce bahsedildiği gibi, RF ya idiyopatiktir ya da skleroderma gibi başka bir hastalığa sekonderdir. Genetik yatkınlığın bu hastalığın bașlangıcına neden olacağı konusunda bazı spekülasyonlar olmuştur. ${ }^{36}$ Yapılan çalıșmalarda, aday genlerde hastalığın etiyolojisinde rol oynadığından şüphe edilen bir mutasyon olmadığı gösterilmiştir. Bu aday genler, kas asetilkolin reseptörü ve serotonin $1 \mathrm{~B}$ ve $1 \mathrm{E}$ reseptörlerinin beta alt birimidir. ${ }^{37}$ Bununla birlikte, yapılan başka bir çalışmada, bu hastalığın prevalansına katkıda bulunan bir genetik faktör olduğu ileri sürülmüştür. $\mathrm{Bu}$ iddia, aile çalışmaları ve ikiz analizi ile desteklenmiştir. ${ }^{38}$ Son zamanlarda, RF tanısı konan 1 aylık bir bebek bildirilmiş ve bu durum, hastalığın genetik temelinin olabileceğini düşündürmüştür. Olguda, trombozun genetik risk faktörleri değerlendirilmiștir. Metilentetrahidrofolat redüktaz (MTHFR) C677T mutasyonu hiperhomosisteinemiyle ilişkili olabilir ve yüksek homosistein düzeylerinin hem hayvan modellerinde hem de insanlarda azalmış vazodilatasyonla ilişkili olduğu gösterilmiştir. RF'li hastaların normal kontrollere göre yüksek homosistein seviyeleri olduğu gösterilmiştir. Bu olguda da hastanın homosistein düzeyleri normal bulunmuştur. Bununla birlikte, MTHFR mutasyonunun kendi içinde vasküler instabilitede doğrudan bir rol oynayıp oynamadığı henüz açıklığa kavuşturulamamıștır. ${ }^{39}$ Bunun sonucunda genetik ve RF arasındaki güçlü bir nedensellik bağlantısı için kanıt eksiktir.

İlginç bir şekilde, vinil klorür monomerine (VCM) maruz birakılan RF hastalar ile ilgili çalışmalar, belirli bir genetik arka plan ile çevresel koşullar arasındaki etkileşimin, VCM'ye maruz kalan bireylerde RF'nin başlamasının rol oynayabileceğini düşündürmektedir. 2006 yılında Fontana ve arkadaşları, glutatyon S-trensferaz M1 ve T1 genlerinde polimorfizm ile VCM'ye maruz kalan RF hastaları arasında bir ilişki olup olmadığını araștırmışlardır. Sonuçlar, her iki gen için pozitif genotiplerin kombinasyonunun RF'ne duyarlılığını arttırabildiğini göstermiştir. ${ }^{40}$ Başka bir çalışmada, 298 mikrosatellit markırlar 
kullanılarak, her aileden en az üç RF hastası olan aileye ait iki aşamalı tam genom taraması gerçekleştirilmiştir. $\mathrm{Bu}$ tarama sonucu olası bağlantılı beş kromozomal alanlar tespit edilmiştir. Bunlar RF ile ilişkilendirilebilecek üç aday gen (kas asetilkolin reseptörü, $1 \mathrm{E}$ ve $1 \mathrm{~B}$ serotonin reseptörlerinin alt birimi) ile eşleştirilmiştir. $\mathrm{Bu} \mathrm{RF}$ duyarlılığı için genetik bir temel kanıt sağlamaktadır. ${ }^{37}$

\section{Raynaud Fenomeni ve Toksikolojik Temeller}

RF'de gözlemlenen artmış vazoreaktivite yanıtlarının birçoğu sempatik veya lokal sebeplerden kaynaklanmaktadır. Soğuk hava veya duygusal kaygı gibi stresler, sempatik kategoriye girmektedir ve bunlar vasokonstrüksiyona neden olmaktadırlar. Öte yandan, mekanik ve kimyasal stresler, hastalığın belirtilerini gösterecek bir vücut organını doğrudan etkiledikleri için "yerel" kategoriye girmektedirler.10 $\mathrm{El}$ ve kol seviyesinde titreşime uzun süreli maruz kalma, mekanik stresin bir örneğidir. Titreşim kaynaklı beyaz parmak olarak da bilinen bu el-kol titreșim sendromu aslında mesleki tehlikelere bağlı olarak bir tür ikincil RF'dir. El ve kolun titreşimli makinelerle sürekli olarak hakaret etmesi, bu organları termal veya duygusal strese bağlı artmış vazospastik ataklara yol açabilmektedir. Bu durumun ilerlemesi oda sıcaklığında bile artmış dijital vazospazma neden olabilmektedir. Bu nedenle, işinde titreşim araçlarını kullanmak isteyen işçilerde vasküler belirtilerin oldukça yaygın olması şaşırtıcı değildir (10). RF'deki kimyasal streslerin önde gelen örneklerinden biri VCM'dir. Bu monomer, özellikle poli vinil klorür (PVC) olmak üzere plastik imalatında kullanılan renksiz bir gazdır. Daha önce de belirtildiği gibi, PVC'ye maruz kalan Fransız işçiler arasında daha yüksek bir RF prevalansı bildirilmiştir. ${ }^{40}$

RF'nin başlangıcına bağlı bazı kimyasal bileşikler ve hatta tıbbi ilaçlar bulunmaktadır. Buna örnek arsenik, nikotin ve gemsitabin verilebilir. Arsenik ve RF arasında pozitif bir korelasyon var gibi görünmektedir. Şili'de yapılan bir çalışmada, $\mathrm{RF}$ de dahil olmak üzere periferik vasküler hastalık belirtilerinin ve semptomlarının yaygınlığının artmasının, arsenik ile kontamine içme suyu ile ilişkili olduğu gösterilmiştir. ${ }^{10}$ Sigara içmenin uzun süredir RF ile pozitif ilişkili olduğu bulunmuştur. Ayrıca, tütünün ana bileșeni olan nikotinin kan akışını önemli ölçüde azalttığı ve damar direncini artırdığı bilinmektedir. Bu nedenle nikotinin $\quad \mathrm{RF}$ semptomlarını şiddetlendirmesi şaşırtıcı değildir. ${ }^{10}$ Kemoterapide kullanılan bir nükleozit analogu olan gemsitabin gibi bazı ilaçlar, RF'ni andiran semptomları uyarabilmektedir. Oral yoldan uygulandığında, bu tür ilaçların tümü $R F^{\prime}$ de tipik olan renklenmelere neden olduğu bildirilmiştir. Mesane kanseri için gemsitabin alındıktan sonra bir RF ve dijital nekroz vakası bildirilmiştir. Ayrıca bir skleroderma hastası, gemsitabin ve karboplatin ile kombine bir tedaviyi aldıktan sonra dijital iskemi gelişmiştir. Gemsitabin ile ilişskili vasküler toksisitenin skleroderma hastalarında daha belirgin olduğunu belirtmek önemlidir. $\mathrm{Bu}$ nedenle, skleroderma veya RF hastalarına kemoterapötik ajanlar, özellikle gemsitabin, uygulanırken dikkatli olunmalıdır. ${ }^{10}$

\section{Sonuç}

Hastalığın multifaktöriyel etiyolojisi (hormonal, nöronal ve endotelyal) nedeniyle hastalığın mekanizmasını açıklamak oldukça zordur. Diğer bir zorluk, hastalığın uygun bir hayvan modelinin bulunmamasıdır. Şimdiye kadar RF'nin soğuk kaynaklı vazospastik ataklarının önemine vurgu yapılmış ve önlem alınmaya çalışılmıştır. Bu hastalığa neden olan birçok faktör açıklanmasına rağmen, RF'nin başlangıcının ve ilerlemesinin altında yatan moleküler mekanizmaların aydınlatılması için daha fazla araştırmaya gereksinim duyulmaktadır.

\section{Kaynaklar}

1.Charkoudian N. Mechanisms and modifiers of reflex induced cutaneous vasodilation and vasoconstriction in humans. J. Appl. Physiol. 2010; 109(1985):1221-1228. 
2.Wigley FM, Flavahan NA.Raynaud's phenomenon.N.Engl.J.Med. 2016;375:556565.

3.Herrick AL. The pathogenesis, diagnosis and treatment of Raynaud phenomenon. Nat. Rev. Rheumatol. 2012;8:469-479.

4.Block JA, Sequeira W. Raynaud's phenomenon. Lancet 2001;357:2042-2048.

5. Roustit M, Khouri C, Blaise S, Villier C, Carpentier P, Cracowski JL. Pharmacology of Raynaud's phenomenon. Therapie 2014;69:115-128.

6. Prete M, Fatone MC, Favoino E, Perosa F. (2014). Raynaud's phenomenon: from molecular pathogenesis to therapy. Autoimmun. Rev. 2014; 13:655-667.

7. Black CM. Systemic sclerosis 'state of the art' 1995. Scand. J. Rheumatol. 1995;24:194196.

8. Garner R, Kumari R, Lanyon P, Doherty M, Zhang W. Prevalence, risk factors and associations of primary Raynaud's phenomenon: systematic review and metaanalysis of observational studies. BMJ 2015; Open 5: e006389.

9. Maverakis E, Patel F, Kronenberg DG, Chung L, Fiorentino D, Allanore $\mathrm{Y}$, et al. (2014). International consensus criteria for the diagnosis of Raynaud's phenomenon. $J$. Autoimmun. 2014;4:60-65.

10. Fardoun MM, Nassif J, Issa K, Baydoun E, Eid AH. Raynaud's Phenomenon: A brief review of the underlying mechanisms. Front. Pharmacol. 2016;7:438.

11. Greenstein D, Jeffcote N, Ilsley D, Kester RC. The menstrual cycle and Raynaud's phenomenon. Angiology. 1996;47:427-436.

12. Wigley FM. Clinical practice. Raynaud's phenomenon. N. Engl. J. Med. 2002;347:1001-1008.

13. Easter M J, Marshall JM. Contribution of prostanoids to endothelium-dependent vasodilatation in the digital circulation of women with primary Raynaud's disease. Clin. Sci. (Lond). 2005;109:45-54.

14. Guimaraes S, Moura D. Vascular adrenoceptors: an update. Pharmacol. Rev. 2001;53:319-356.
15. Ahles A, Engelhardt S. Polymorphic variants of adrenoceptors: pharmacology, physiology, and role in disease. Pharmacol. Rev. 2014;66:598-637.

16. McCance KL, Huether SE. Pathophysiology: The Biologic Basis for Disease in Adults and Children. Amsterdam: Elsevier. 2013.

17. Polonia JJ., Paiva MQ, Guimaraes S. Pharmacological characterization of postsynaptic alpha-adrenoceptor subtypes in five different dog arteries in-vitro. J. Pharm. Pharmacol. 1985;37:205-208.

18. Johnson JM, Kellogg DLJr. Local thermal control of the human cutaneous circulation. J. Appl. Physiol. 2010;109:1229-1238.

19. Freedman RR, Sabharwal SC, Moten M, Migaly P. Local temperature modulates alpha 1- and alpha 2-adrenergic vasoconstriction in men. Am. J. Physiol. 1992;263:H1197H1200.

20. MacDonald E, Kobilka BK, Scheinin M. Gene targeting-homing in on alpha2adrenoceptor-subtype function.Trends Pharmacol. Sci. 1997;18:211-219.

21. Chotani MA, Flavahan S, Mitra S, Daunt D, Flavahan NA. Silent alpha(2C)-adrenergic receptors enable cold-induced vasoconstriction in cutaneous arteries. Am. J. Physiol. Heart Circ. Physiol. 2000;278:H1075-H1083.

22. Sallinen J, Link RE, Haapalinna A, Viitamaa T, Kulatunga M, Sjoholm B, et al. Genetic alteration of alpha $2 \mathrm{C}$-adrenoceptor expression in mice: influence on locomotor, hypothermic, and neurochemical effects of dexmedetomidine, a subtype-nonselective alpha 2-adrenoceptor agonist. Mol. Pharmacol. 1997;51:36-46.

23. Jeyaraj SC, Chotani MA, Mitra S, Gregg HE, Flavahan NA, Morrison KJ. Cooling evokes redistribution of alpha2C-adrenoceptors from Golgi to plasma membrane in transfected human embryonic kidney 293 cells. Mol. Pharmacol. 2001;60:1195-1200.

24. Bailey SR, Eid AH, Mitra S, Flavahan S, Flavahan NA. Rho kinase mediates coldinduced constriction of cutaneous arteries: role of alpha2C-adrenoceptor translocation. Circ. Res. 2004;94:1367-1374. 
25. Maricq HR, Carpentier PH, Weinrich MC, Keil JE, Franco A, Drouet P, et al. Geographic variation in the prevalence of Raynaud's phenomenon: Charleston, SC, USA, vs Tarentaise, Savoie, France. J. Rheumatol. 1993;20:70-76.

26. Belch JJF, Ho M. "Vasospastic disorders and vasculitis," in Vascular and Endovascular Surgery, eds J. D. Beard and P. A. Gaines (London: WB Saunders and Company). 2001;217-240.

27. Garner R, Kumari R, Lanyon P, Doherty M, Zhang W. Prevalence, risk factors and associations of primary Raynaud's phenomenon: systematic review and metaanalysis of observational studies. BMJ Open 5. 2015; $\mathrm{e} 006389$.

28. Mayes MD. Epidemiologic studies of environmental agents and systemic autoimmune diseases. Environ. Health Perspect. 1999;107(Suppl. 5):743-748.

29. Fraenkel L, Zhang Y, Chaisson CE, Evans SR, Wilson PW, Felson DT. The association of estrogen replacement therapy and the Raynaud phenomenon in postmenopausal women. Ann. Intern. Med. 1998;129:208211.

30. Chan NN, MacAllister RJ, Colhoun HM, Vallance $\mathrm{P}$, Hingorani AD. Changes in endothelium-dependent vasodilatation and alpha- adrenergic responses in resistance vessels during the menstrual cycle in healthy women. J. Clin. Endocrinol. Metab. 2001;86:2499-2504.

31. Li T, Xiao X, Zhang J, Zhu Y, Hu Y, Zang J, et al. Age and sex differences in vascular responsiveness in healthy and trauma patients: contribution of estrogen receptormediated Rho kinase and PKC pathways. Am. J. Physiol. Heart Circ. Physiol. 2014;306:H1105-H1115.

32. Charkoudian N, Stachenfeld N. Sex hormone effects on autonomic mechanisms of thermoregulation in humans. Auton. Neurosci. 2016;196:75-80.

33. Flavahan, N. A. A vascular mechanistic approach to understanding Raynaud phenomenon. Nat. Rev. Rheumatol. 2015;11:146-158.
34. English KM, Jones RD, Jones TH, Morice $\mathrm{AH}$, Channer KS. Gender differences in the vasomotor effects of different steroid hormones in rat pulmonary and coronary arteries. Horm. Metab. Res. 2001;33:645652.

35. Eid AH, Maiti K, Mitra S, Chotani MA, Flavahan S, Bailey SR, et al. Estrogen increases smooth muscle expression of alpha2C-adrenoceptors and cold-induced constriction of cutaneous arteries. Am. J. Physiol. Heart Circ. Physiol. 2007;293:H1955-H1961.

36. Tan FK, Arnett FC. Genetic factors in the etiology of systemic sclerosis and Raynaud phenomenon. Curr. Opin. Rheumatol. 2000;12:511-519.

37. Susol E, MacGregor AJ, Barrett JH, Wilson $\mathrm{H}$, Black C, Welsh $\mathrm{K}$, et al. A two-stage, genome-wide screen for susceptibility loci in primary Raynaud's phenomenon. Arthritis Rheum. 2000;43:1641-1646.

38. Pistorius MA, Planchon B, Schott JJ, Lemarec H. [Heredity and genetic aspects of Raynaud's disease]. J. Mal. Vasc. 2006;31:1015.

39. Sharathkumar AA, Castillo-Caro P. Primary Raynaud's phenomenon in an infant: a case report and review of literature. Pediatr. Rheumatol. Online J. 2011;9:16.

40. Fontana L, Marion MJ, Ughetto S, Catilina P. Glutathione S-transferase M1 and GST T1 genetic polymorphisms and Raynaud's phenomenon in French vinyl chloride monomer-exposed workers. J. Hum. Genet. 2006;51:879-886. 